
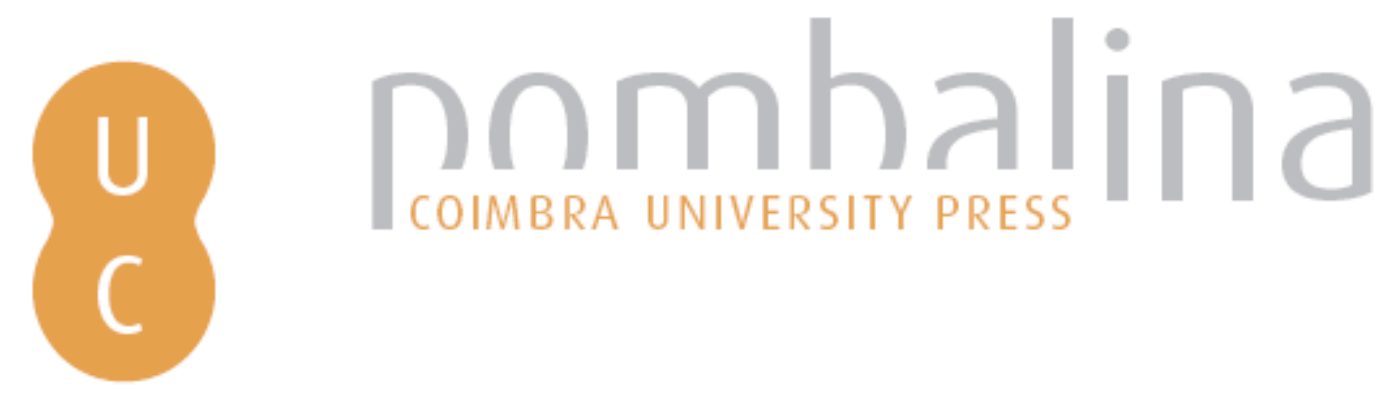

\title{
Dissertações einsteinianas em Portugal (1911-1930)
}

Autor(es): $\quad$ Martins, Décio Ruivo

Publicado por: Imprensa da Universidade de Coimbra

URL

persistente: URI:http://hdl.handle.net/10316.2/32493

DOI: $\quad$ DOI:http://dx.doi.org/10.14195/978-989-26-0353-7_6

Accessed : $\quad$ 26-Apr-2023 10:55:28

A navegação consulta e descarregamento dos títulos inseridos nas Bibliotecas Digitais UC Digitalis, UC Pombalina e UC Impactum, pressupõem a aceitação plena e sem reservas dos Termos e Condições de Uso destas Bibliotecas Digitais, disponíveis em https://digitalis.uc.pt/pt-pt/termos.

Conforme exposto nos referidos Termos e Condições de Uso, o descarregamento de títulos de acesso restrito requer uma licença válida de autorização devendo o utilizador aceder ao(s) documento(s) a partir de um endereço de IP da instituição detentora da supramencionada licença.

Ao utilizador é apenas permitido o descarregamento para uso pessoal, pelo que o emprego do(s) título(s) descarregado(s) para outro fim, designadamente comercial, carece de autorização do respetivo autor ou editor da obra.

Na medida em que todas as obras da UC Digitalis se encontram protegidas pelo Código do Direito de Autor e Direitos Conexos e demais legislação aplicável, toda a cópia, parcial ou total, deste documento, nos casos em que é legalmente admitida, deverá conter ou fazer-se acompanhar por este aviso.

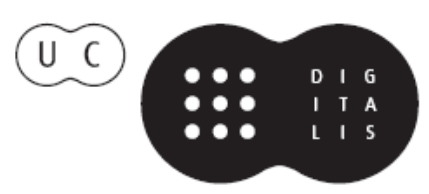




\section{CARLOS FIOLHAIS}

Coordenaç̃o

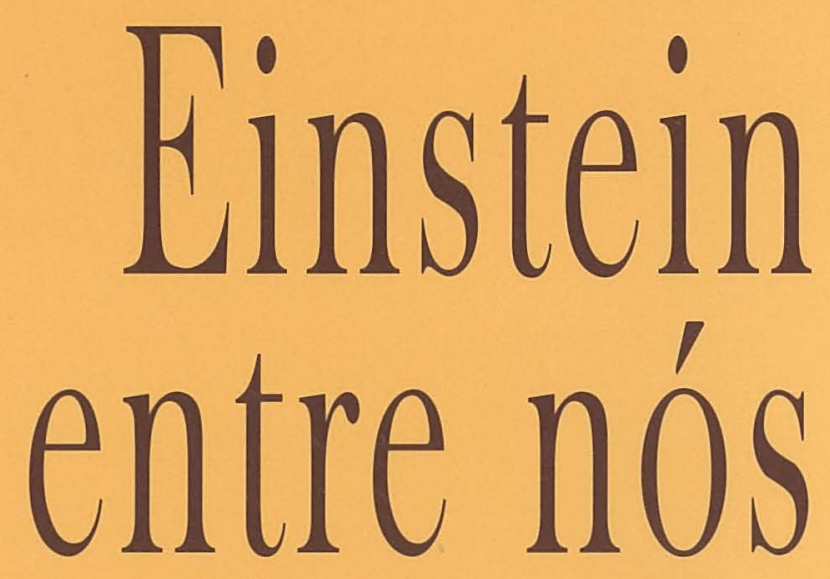

A recepcão de Einstein em Portugal

de 1905 a 1955

Coimbra Imprensa da Universidade $\quad 2005$ 
(Página deixada propositadamente em branco) 


\section{CARLOS FIOLHAIS}

Coordenação

\section{Einstein entre nós}

A recepscão de Einstein em Portugal

de 1905 a 1955

Coimbra I I prensa da Universidade $\quad 2005$ 


\section{Coordenação editorial}

Imprensa da Universidade de Coimbra

\section{Concepção gráfica}

António Barros

\section{Digitalização de imagens}

Alexandre Ramires

Museu de Ciência da Universidade de Lisboa

Paginação

SerSilito

\section{Execução gráfica \\ SerSilito - Maia}

\section{ISBN}

972-8704-60-7

\section{Depósito legal \\ 233349/05}

Outubro de 2005

(C) 2005, Imprensa da Universidade de Coimbra

\section{Apoios:}

Departamento de Física da Faculdade de Ciências e

Tecnologia da Universidade de Coimbra

Sociedade Portuguesa de Física

Associação para o Desenvolvimento do Departamento de Física (ADDF)

Programa Operacional Ciência e Inovação 2010

Museu de Ciência da Universidade de Lisboa 


\section{DissertaÇões einsteinianas em Portugal (1911-1930)}

\section{Décio Ruivo Martins ${ }^{(*)}$}

A repercussão dos trabalhos publicados por Einstein no annus mirabilis de 1905 não se fez sentir em Portugal, senão com algum atraso. Isto não significa, contudo que as descobertas e teorias científicas de finais do século XIX e início do século XX não fossem objecto de interesse da comunidade científica portuguesa. Pode mesmo afirmar-se que a Portugal chegavam as mais prestigiadas publicações internacionais. As primeiras experiências sobre os raios X e a sua aplicação no diagnóstico clínico foram feitas em Coimbra pouco mais de um mês depois do anúncio de sua descoberta. Em 1908 Egas Ferreira Pinto Basto, na sua dissertação sobre a Theoria dos Electrões, referia-se às descargas eléctricas produzidas pela acção da luz ultravioleta ou efeito fotoeléctrico. Neste trabalho Pinto Basto mostrava que conhecia os mais recentes estudos de Joseph John Thomson e Ernest Rutherford. No entanto, terá sido apenas em 1912 que foi feita a primeira referência à Teoria da Relatividade, num documento escrito por Leonardo Coimbra, tendo como referência um artigo publicado por Paul Langevin nesse mesmo ano. Alguns trabalhos sobre este assunto, apenas esparsamente publicados nos anos vinte, deixam transparecer uma notória indiferença inicial ao tema na comunidade científica portuguesa.

Para uma melhor compreensão das condições de receptividade dos novos conhecimentos científicos, e também do modo e importância como o

(*) Departamento de Física e Centro de Física Computacional da Universidade de Coimbra. 
tema da relatividade despontou em Portugal, convém que a análise seja inserida num contexto mais abrangente da produção científica portuguesa, particularmente na área da Física. Para isso, podemos tomar como referência as Faculdades de Filosofia e de Matemática da Universidade de Coimbra.

\section{A Física em Coimbra até 1925}

A produção científica em Portugal no início do século XX não atingiu o brilhantismo observado noutros países europeus. Contudo, as viagens científicas ao longo de toda a segunda metade do século XIX e início do século XX, realizadas pelos professores das Faculdades de Filosofia e de Matemática da Universidade de Coimbra, posteriormente Faculdade de Ciências, possibilitaram o contacto com os mais conceituados centros universitários europeus, tendo algum reflexo no ensino e na natureza dos temas abordados nas teses académicas. António dos Santos Viegas terá sido, entre os físicos portugueses, aquele que, ao longo de toda segunda metade do século XIX, mais contribuiu para promover o desenvolvimento do ensino e incentivar a produção científica de jovens licenciados. Este professor manteve-se ligado ao ensino da Física durante mais de cinquenta anos, durante os quais visitou várias universidades europeias. Sob a sua influência, o ensino experimental da Física teve um desenvolvimento considerável, traduzido quer pela qualidade e quantidade de instrumentos adquiridos, quer pelos programas das cadeiras do Curso de Filosofia. A notável colecção de instrumentos do Gabinete de Física Experimental é uma demonstração do grau de actualidade com que os diversos temas da ciência eram tratados no ensino. Este facto pode ser comprovado pelos programas de ensino elaborados por António dos Santos Viegas ${ }^{(1)}$ e António de Meireles Garrido ${ }^{(2)}$ do ano académico de 1889 - 1890, ou os Summarios das lições de Henrique Teixeira Bastos do ano de $1906^{(3)}$. Mesmo assim, o nível de desenvolvimento do ensino desta disciplina esteve

(1) Programma da 3a cadeira de Physica, la parte, para o anno lectivo de 1889 a 1890. Coimbra : Impr. da Universidade, 1889.

(2) Programma da 5a cadeira de Physica, 2a parte para o anno lectivo de 1889 a 1890. Coimbra : Impr. da Universidade, 1889.

(3) Óptica e Electricidade. Summarios das lições Professor H. Teixeira Bastos. F. França Amado - Editor, 1906. 
sempre aquém dos anseios dos respectivos professores. Com efeito, desde meados do século XIX começaram a surgir opiniões de o que o desenvolvimento observado na Física justificava que as suas diversas áreas de especialidade tivessem correspondência em disciplinas autónomas. Este foi, contudo, um desígnio não cumprido.

Por outro lado, considerando a complementaridade pedagógica da organização curricular das Faculdades de Filosofia e Matemática, verificou-se que para além das cadeiras de Física Experimental do Curso de Filosofia, também a Faculdade de Matemática contemplava o ensino teórico de algumas áreas da Física, através de cadeiras que constituíam as designadas matemáticas mistas ou ciências físico-matemáticas. ${ }^{(4)}$ Esta foi uma prática observada desde 1772, quando foram criadas as duas Faculdades. ${ }^{(5)}$ Esta organização curricular acabou por ter reflexos na reforma de 1911, que resultou na fusão das duas Faculdades, dando origem à Faculdade de Ciências. Pode dizer-se que, segundo a tradição do século XIX, as questões teóricas da Física eram tratadas pelos físico-matemáticos da Faculdade de Matemática. Daqui se justifica o facto dos matemáticos terem dado um maior relevo à Teoria da Relatividade, do que a importância que lhe foi atribuída pelos professores de Física ${ }^{(6)}$. Um exemplo é o da dissertação de concurso para professor catedrático do $2^{\circ}$ grupo da $1^{\underline{a}}$ secção da Faculdade de Ciências, subordinada ao tema O Problema da Gravitação Universal, submetida por Manuel dos Reis, em Fevereiro de 1933. Neste trabalho, após uma referência às ideias teóricas que, desde a antiguidade, contribuíram para os progressos da Astronomia e da Física, e que prepararam lentamente o aparecimento da teoria da gravitação de Newton, foi feito um tratamento breve das teorias da gravitação propostas desde Newton até à Teoria da Relatividade Restrita. Seguia-se a análise das dificuldades da Física que estiveram na base da elaboração da teoria. Foi consagrado um capítulo à exposição das bases da Teoria da Relatividade Restrita e dos seus resultados. Também foi apresentada uma sistematização dos princípios da dinâmica analítica relativista dos sistemas de pontos materiais, seguindo-se as teorias da gravitação que apareceram sob a influência da Teoria da Relatividade especial, ou das que, como as de Lorentz e Poincaré, se adaptavam a esta teoria sem modificações essenciais. Por fim, o último capítulo da

\footnotetext{
(4) MARTINS, Décio Ruivo (2001) p. 333 - 34.5.

(5) MARTINS, Décio Ruivo (2000) p. 193 - 262.

(6) FITAS, Augusto J. Santos - (2004). p. 5-6.
} 
dissertação era dedicado à teoria da gravitação de Einstein. Para além de Manuel dos Reis, também Francisco Costa Lobo dedicou-se aos aspectos teóricos da Física, do que é exemplo o seu trabalho intitulado Theories in Physics resulting from the Phenomena of Radioactivity, publicado em 1931 na Revista da Faculdade de Ciências, artigo que viria posteriormente a ser contestado por Mário Silva e Egas Pinto Basto, num artigo publicado na mesma revista em 1932, com o título La Theorie physique basée sur les phenomenes de radiocativité, du Dr. F.M. da Costa Lobo.

Apesar de não serem em grande número, podemos encontrar alguns trabalhos na área da Física e Química, que denotam, contudo, um acompanhamento actualizado do desenvolvimento da ciência no fim do século XIX e início do século XX. Com efeito, no ano de 1879 foi publicada no Porto uma obra póstuma da autoria de António Luiz Ferreira Girão, cujo título era $A$ Theoria dos Atomos e os Limites da Sciencia. Este antigo estudante das Faculdades de Mathematica e de Philosophia da Universidade de Coimbra foi sócio correspondente da Academia Real das Ciências de Lisboa, Membro do Instituto Literário de Coimbra, lente de Química na Academia Politécnica do Porto e professor de Mineralogia no Instituto Industrial do Porto. No seu trabalho era feita referência à transmutação dos metais, estudos recentes sobre radicais compostos, fenómenos ópticos, dissociação dos gases a altas temperaturas e análise espectral dos corpos celestes.

O Congresso de Electricidade, reunido em Paris em Setembro de 1881, no qual Portugal foi representado por António dos Santos Viegas, teve por objectivo fundamental o estabelecimento da uniformidade das unidades eléctricas. O profundo conhecimento que este professor tinha da organização do ensino universitário em vários países da Europa e o contacto que estabeleceu com cientistas de grande prestígio reflectiu-se no ensino e na qualidade científica das teses e dissertações submetidas à Faculdade, principalmente na área da Física. Em Maio de 1884 Henrique Teixeira Bastos apresentou uma dissertação inaugural para o acto de Conclusões Magnas integralmente dedicada à definição de um sistema racional de unidades eléctricas e definição de padrões eléctricos de resistência e de força electromotriz. Em Fevereiro do ano seguinte, submeteu a sua dissertação de concurso apresentada à Faculdade de Philosophia sobre a Theoria Electromagnetica da Luz. No dia 3 de Julho de 1886, foram analisadas e aprovadas as Theses e Dissertação Inaugural submetidas por Aarão Ferreira de Lacerda. A dissertação inaugural era subordinada ao título Equações Geraes da Thermodynamica e foi defen- 
dida no dia 30 de Outubro de 1886 perante um júri presidido por António dos Santos Viegas. Em 1896 Teixeira Bastos publicou um artigo na revista científica $O$ Instituto, onde anunciava as mais recentes descobertas relativas aos raios de Röntgen. Em Fevereiro de 1896, pouco mais de um mês depois da descoberta dos raios $\mathrm{X}$, fizeram-se as primeiras experiências em Coimbra. No dia 1 de Março de 1896, o jornal O Século publicou na primeira página um extenso artigo intitulado A Photographia atravez dos corpos opacos, onde se dava uma notícia das primeiras experiências feitas em Portugal. Desde o princípio da década de 1850 que a experimentação em descargas eléctricas em gases e o estudo de espectros de emissão interessou os professores de Física Experimental. Este facto explica a existência dos recursos necessários para a realização imediata das experiências. A quase totalidade do equipamento utilizado em Fevereiro de 1896 nas primeiras experiências dos raios $\mathrm{X}$ tinha sido adquirida em 1872, isto é, 24 anos antes. Parte deste valioso espólio ainda existe no Museu de Física. Ainda durante o mês de Fevereiro foram feitos ensaios de utilização dos raios X no diagnóstico clínico.

Nos anos de 1896 e 1897 intensificaram-se os estudos sobre os raios catódicos e os raios X no Gabinete de Física de Coimbra. Em Maio de 1897 o licenciado em Philosophia Natural Álvaro José da Silva Basto submeteu a dissertação inaugural para o acto de conclusões magnas na Faculdade de Philosophia intitulada $O$ s raios cathódicos e os raios $X$ de Röntgen. Silva Basto começava por se referir aos estudos experimentais de descargas eléctricas em gases, descrevendo pormenorizadamente a aparência das descargas em diversas condições, métodos de preparação das descargas, seguindo-se o estudo experimental dos raios catódicos e descrição do estado eléctrico dos tubos de descarga. Sobre as propriedades dos raios catódicos, referia-se às suas acções luminescentes, acções químicas e fotográficas, mecânicas, caloríficas e acções eléctricas. Estudou a acção de um campo magnético e de um campo electrostático sobre os raios catódicos. Estudos sobre a propagação no interior do tubo, determinação da velocidade, reflexão e transparência, propagação no exterior do tubo (experiências de Lenard) também eram contemplados na sua dissertação. A parte referente aos raios de Röntgen iniciava-se com um estudo sobre as suas propriedades ópticas, seguindo-se experiências sobre acções luminescentes e fotográficas, acções eléctricas e o estudo comparativo com outras radiações novas como os raios de Bequerel. Depois de um capítulo dedicado aos modelos teóricos explicativos da natureza dos raios $\mathrm{X}$, desenvolveu o estudo das técnicas de produção e de aplicação. Entre a 
extensa bibliografia publicada na Europa e nos Estados Unidos, referenciada na tese defendida em Coimbra, merecem destaque especial pela sua actualidade as comunicações apresentadas na Academia das Ciências de Paris por Perrigot, no dia 20 de Abril de 1897, publicada no Compte Rendus (p. 857), por Gustav Le Bom, em 26 de Abril (p. 892), e de Henri Bequerel, datada de 10 de Maio do mesmo ano (p. 984). Se considerarmos que Silva Basto concluiu a redacção da sua dissertação em Maio desse ano, conclui-se que a última comunicação foi apresentada em Paris cerca de vinte dias antes de concluir o seu estudo!

O final do século XIX e o início do século XX ficou assinalado na Faculdade de Filosofia pela introdução dos estudos experimentais mais recentes sobre a constituição atómica da matéria. Na verdade, em 1908 foi apresentada a dissertação inaugural para o acto de Conclusões Magnas na secção de Sciencias Physico-chimicas da Faculdade de Philosophia, da autoria de Egas Ferreira Pinto Basto. No mesmo ano submeteu uma nova dissertação para o concurso ao magistério na primeira secção da Faculdade de Philosophia Natural, a qual era uma continuação do seu estudo sobre a Theoria dos Electrões. Este trabalho é bem elucidativo da actualidade com que alguns assuntos da Física Moderna eram tratados em Coimbra. Na primeira parte da sua dissertação, Pinto Basto referia-se ao estudo experimental dos raios catódicos, incluindo a sua produção e propriedades, natureza dos raios catódicos, determinação da velocidade dos raios catódicos e do valor e/m. No capítulo dedicado ao estudo experimental da ionização dos gases fazia referência às descargas eléctricas produzidas pela acção da luz ultravioleta ou efeito fotoeléctrico, ao estudo experimental dos raios canais e determinação da carga e massa dos iões. Um capítulo era dedicado às radiações emitidas pelas substâncias radioactivas, referindo-se às propriedades dos raios $\alpha, \beta$ e $\gamma$. A segunda parte do seu trabalho iniciava-se com o estudo do fenómeno de Zeeman, constituição do átomo, teorias sobre a condutibilidade metálica, referindo-se aos efeitos de Peltier e de Hall, arranjo dos electrões no átomo de acordo com os resultados experimentais, referindo-se ao modelo do japonês Nagaoka (1903), do qual tomou conhecimento através de dois artigos publicados na revista Nature, em 25 de Fevereiro e 9 de Julho de 1904. A maior parte do trabalho tinha como referência os estudos mais recentes de Joseph John Thomson e Ernest Rutherford, analisando assuntos como a lei periódica, propriedades electroquímicas e valência, radioactividade, determinação do número de electrões existentes num átomo e a sua distribuição em anéis segundo o modelo 
de Thomson, determinação das dimensões da esfera de electricidade positiva, origem da massa do átomo, etc.

Refira-se ainda que em 1906, João de Magalhães apresentou a sua tese de licenciatura subordinada ao tema $O$ Rádio e a Radioactividade ${ }^{(7)}$. Sobre este assunto, o jovem licenciado viria a publicar, nos anos de 1906 e 1907, onze artigos no Instituto ${ }^{(8)}$. Alguns anos depois, ainda sobre os estudos experimentais das radiações ionizantes, o professor Souza Nazareth submeteu, em 1915, dissertação para o concurso de Segundo Assistente do $1^{\circ}$ grupo da $2^{\mathrm{a}}$ secção da Faculdade de Ciências da Universidade de Coimbra subordinada ao tema Ionisação dos gases em vaso fechado. ${ }^{(9)}$ Segundo Mário Silva, o seu antigo professor esteve muito próximo de descobrir uma partícula nuclear: o neutrão.

Um nome incontornável de notoriedade e actualização científica, resultante dos contactos com os mais prestigiados centros de investigação europeus da época, foi Mário Silva que se licenciou em 1922 e em 1925 partiu para Paris, onde ambicionava prosseguir os seus estudos e trabalhar no Instituto do Rádio, criado e dirigido por Marie Curie, tendo-se doutorado sob a sua orientação pela Universidade de Paris em 1928 com a menção: très honorable. Defendeu a tese intitulada Recherches Expérimentales sur l'Électroaffinité des $\mathrm{Gaz}$, da qual foram júri três grandes cientistas franceses: Marie Curie (Presidente), Jean Perrin e Debierne. Na capital francesa estudou com matemáticos eminentes como Édouard Goursat, Jacques Hadamard e Émile Borel e com os famosos físicos Paul Langevin e Louis de Broglie. No Instituo do Rádio, Mário Silva conheceu pessoalmente Einstein, Niels Bohr, Lorentz, J. J. Thomson e Holweck, entre muitos outros cientistas. Entre os textos didácticos que publicou salientam-se os seguintes: Mecânica Física (princípios fundamentais) (Newton-Einstein), em 1945; Teoria do Campo Electromagnético (Maxwell-Lorentz-Einstein), em 1945; O significado da Relatividade, de Albert Einstein, em 1958, com uma «Explicação Prévia» do Prof. Mário Silva.

António dos Santos Viegas morreu em 1914, com 79 anos de idade. Quase até ao fim da sua vida manteve uma intensa actividade ligada ao ensino da Física Experimental. Destes factos, depreende-se que conseguiu, efectivamente, lançar as bases para uma actividade científica que não desmerecia em relação às descobertas mais recentes na área da Física. Os seus mais directos

\footnotetext{
(7) MAGALHÃES, João de - (1906).

(8) MAGALHÃES, João de - (1906 - 1907).

(9) NAZARETH, Francisco Martins de Souza - (1915).
} 
discípulos e aqueles que o sucederam no ensino deram continuidade ao seu projecto. Do ambiente científico que se vivia nas Faculdades de Filosofia e de Matemática, conclui-se que estavam reunidas as condições para que a Teoria da Relatividade pudesse ter sido abordada em Coimbra com o mesmo grau de actualidade com que outros temas foram tratados. A verdade é que só mais tardiamente começaram a aparecer as primeiras referências sobre este assunto. Talvez este facto se possa explicar pela avaliação pouco favorável feita por Costa Lobo a respeito da teoria de Einstein.

\section{Dissertações einsteinianas (1911 - 1930)}

\section{Costa Lobo}

Não são notados reflexos imediatos em Portugal no ensino das ciências físico-matemáticas em consequência dos trabalhos de Einstein. $\mathrm{O}$ artigo intitulado Explicação Física da Atracção Universal terá sido o primeiro texto da autoria de professores da Universidade de Coimbra contendo referências a Einstein e à Teoria da Relatividade Generalizada. Foi publicado por Costa Lobo no Instituto apenas em 1917, embora a teoria da gravitação tenha sido anteriormente objecto de uma comunicação sua num Congresso de Granada, em Junho de 1911, onde apresentou o tema - As radiações e atracção neutoniana. A teoria radiante que então expôs tinha por base a radioactividade, e a sua generalização a todos os fenómenos observados. Na comunicação de 1911, fazendo a classificação das radiações, Costa Lobo apresentou a seguinte doutrina: ${ }^{(10)}$

Por imponderáveis designo, e, creio com a maior propriedade, as radiações que produzem o fenómeno da gravidade, ou melhor, da atracção, que nunca deveria ser considerado como derivado de uma qualidade intrínseca da matéria, mas sim dever encontrar explicação na constituição do universo. Esta explicação deduzo-a do facto constatado da passagem da matéria para o estado radiante caracterizado por prodigiosas velocidades de translação, e da consideração da hipótese de num dado momento toda a matéria se encontrar neste estado, e da formação da matéria atómica como consequência dos choques dessas radiações.

(10) LOBO, Costa - (1917). p. 611-613. 
Segundo Costa Lobo, admitidos estes princípios, seria fácil chegar a uma explicação física da atraç̧ão universal. A matéria assim formada num dado lugar, além de ficar com as propriedades que resultavam do movimento das radiações que a produziram, constituiria uma enorme condensação de energia, a qual provocaria a correspondente reacção das radiações, que, segundo ele, exerciam sobre aquele centro de condensação um efeito análogo ao de uma pressão. Preconizava uma explicação física da atracção universal, fundamentada no princípio de que a aç̧ão não é instantânea, mas sim é transmitida com a velocidade da luz. Costa Lobo declarava, contudo que a sua teoria não concordava com a formulada por Einstein. No entanto, considerava que noutros aspectos havia uma concordância. Tendo como referência um artigo publicado por Einstein, em Novembro desse mesmo ano, no Bulletin de la Société Astronomique de France, Costa Lobo afirmou o seguinte: ${ }^{(1)}$

Para melhor apreciar quanto a explicação que apresento diverge da doutrina de Einstein, transcrevo da tradução da sua memória original, publicada nos arquivos das ciências físicas e naturais de Genebra, reproduzida no Bulletin de la Société Astronomique de France de Novembro último, os seguintes períodos:

"Uma outra consequência da hypotese da equivalência - consequência de um alcance fundamental - encontra-se no facto de sofrerem os raios luminosos uma curvatura quando passam n'um campo gravítico. Por exemplo, quando um raio luminoso passa na vesinhança do sol, a curvatura attinge 0",84, quantidade que não é inacessível à experiência».

«Esta consequência arrasta a seguinte: a velocidade da luz n'um campo de gravitação não pode ser constante, deve variar com o lugar».

Comparando as datas da publicação do artigo de Einstein (Novembro de 1917), referido por Costa Lobo, e a do artigo publicado no volume 61 do Instituto (1917), conclui-se que o professor de Coimbra se mantinha ao corrente das mais recentes publicações internacionais na sua área de especialidade. Embora este brevíssimo artigo não seja conclusivo, Costa Lobo pretendeu fazer notar o modo como fundamentalmente a sua doutrina tinha

(11) LOBO, Costa - (1917). p. 613. 
importantes pontos de contacto com a de Einstein sobre a constituição do Universo, até ao ponto em que os novos conhecimentos permitiam chegar. Mas a verdade é que não se mostrou entusiasmado pela Teoria da Relatividade, considerando-a uma doutrina interessante derivada por cálculos admiráveis, mas sem interesse para o mundo físico. ${ }^{(12)}$

\section{Leonardo Coimbra}

Foi baseado em dois trabalhos da autoria de Paul Langevin que Leonardo Coimbra, no ano de 1912, na sua dissertação Criacionismo (esboço de um sistema filosófico), incluiu uma seç̧ão que terá sido a primeira referência escrita em Portugal à Teoria da Relatividade. Neste trabalho eram analisados os conceitos de espaço e tempo. Posteriormente, em Setembro de 1922, Leonardo Coimbra publicou na revista Águia o texto intitulado As doutrinas de Einstein, seu valor scientífico e filosófico. No ano seguinte voltaria a este tema, desenvolvendo-o no livro intitulado A razão Experimental. ${ }^{(13)}$

O primeiro artigo de Langevin, usado como referência por Leonardo Coimbra, tinha por título L'Évoluiton de L'Éspace et du Temps, foi publicado em Julho de 1911 na Revue de Metaphysique et Morale (vol 4. p. 455 - 466), e o segundo, intitulado Les temps et la causalité dans la physique contemporaine apareceu no Bulletin de la Societé Française de Philosophie, de Janeiro de 1912 (12, p. 1 - 46). Este facto serve para confirmar a actualidade com que alguma literatura especializada chegava a Portugal e era utilizada nos meios académicos. Tendo Langevin como referência, Leonardo Coimbra afirmava que o princípio da relatividade do movimento da mecânica clássica permanecia válido, mudando, no entanto, o sentido das noções de espaço e tempo. Aí era afirmado que a hipótese de Lorentz e FitzGerald se encontrava em contradição com as noções habituais do espaço e do tempo. Primeiro Langevin expunha a experiência de Michelson e Morley, demonstrativa da equivalência das diversas direcções no ponto de vista da propagação da luz. Depois demonstrava que este resultado é incompatível com as noções habituais de espaço e de tempo, se conservarmos a teoria das ondulações em óptica. ${ }^{(14)}$

\footnotetext{
(12) FITAS, Augusto J. Santos - (2004). p. 6.

(13) FITAS, Augusto J. Santos - (2004). p. 4.

(14) COIMBRA, Leonardo - (1983). p. 103.
} 
Reflectindo sobre as novas ideias, Leonardo Coimbra comentava que certas noções da física moderna levantavam, aparentemente, pelo menos, dificuldades à sistematização pelas velhas noções mecânicas e energéticas. ${ }^{(15)}$ Principalmente porque os estudos mais recentes conduziam à instabilidade das teorias físicas. Considerava que se as novas teorias, suficientemente cómodas e fecundas para serem verdadeiras, condenam os antigos princípios, esses princípios terão de desaparecer. Contudo, questionava o facto de que, nalguns aspectos, os novos conceitos ainda mantinham alguma relação de dependência relativamente às noções antigas. Neste sentido, questionava-se: como demonstrar a falsidade dos antigos princípios pelas novas teorias se para o aparecimento das novas teorias foram precisos os antigos princípios? Dentro das mais recentes teorias da matéria, a massa é, a partir de certas velocidades função da velocidade. Assim, a massa, constante abaixo duma certa velocidade mínima, é variável após esse limite. Leonardo Coimbra interrogava: se a física não é uma arquitectura de noções, como compreender esta dualidade? Na sua opinião, não serve de nada dizer que o antigo princípio da invariabilidade da massa é substituído pelo prinć́pio da massa função da velocidade. Para Leonardo Coimbra, a ciência de convenções cómodas teria de se contentar do facto da massa ser independente da velocidade para as velocidades afastadas da velocidade da luz. Para ele, esse facto era o milagre insubsistente, que nada garante, nem explica. Não deixava de expressar a sua estranheza pelo facto das teorias electromagnéticas serem a causa da negação da massa, que, em sólidos alicerces, sustentava o edifício da Física. Deste modo, a massa mecânica é negada, mas envolvida no determinismo superior da massa electromagnética. A independência da massa perante velocidades pequenas deixava de ser um miraculoso facto para ser uma necessidade racional. ${ }^{(16)}$

Leonardo Coimbra recordava o facto de que a mecânica clássica considerava a velocidade como o mais simples elemento e das suas variações resultavam as qualidades específicas do movimento. Justificava-se, por esse motivo, o destaque dado ao conceito da aceleração em todo o campo da antiga teorização mecânica. Partindo do repouso, a primeira modificação é a velocidade, que será simples ou se oferecerá como novo homogéneo às novas complicações da aceleração. Mas, sendo o repouso relativo, todo o início era arbitrário, só jus-

(15) COIMBRA, Leonardo - (1983). p. 93.

(16) COIMBRA, Leonardo - (1983). p. 101. 
tificável pelo pragmatismo natural do conhecimento. Assim, na relatividade do repouso ou do movimento, surgia um novo homogéneo a oferecer-se ao determinismo do conhecimento: o do movimento de translação uniforme. ${ }^{(17)}$ Leonardo Coimbra salientava o facto de que crentes na realidade do sólido rígido e indeformável, os físicos não duvidaram da transmissão instantânea de abalos do repouso, seja da possibilidade física de uma velocidade infinita. $\mathrm{O}$ estabelecimento de um limite para a velocidade de transmissão dos abalos relegaria a antiga mecânica a uma mera aproximação no contexto de uma teoria mais abrangente. Leonardo Coimbra expressou a opinião de que:(18)

... assim não seria de admirar que a realidade da experiência desmentindo o vago de suas abstracções, dando-lhe o correctivo de uma velocidade limite, viesse mostrar como o grupo de Galileu e seus invariantes são apenas aproximações felizes, do grau de felicidade dependente da pequenez das velocidades estudadas em relação àquele limite.

Essa velocidade limite é a velocidade da luz: $300.000 \mathrm{~km} / \mathrm{s}$; imensa, com efeito, em relação às velocidades da mecânica clássica - como que fazendo o papel de infinita.

Segundo Leonardo Coimbra, a ideia genial de Einstein consistiu em reduzir as forças de gravitação a forças de inércia, de modo que o Universo einsteiniano surgiu com a complicação mais alta, a forma mais completa e definida da inércia: a inércia de Galileu substituída por uma nova e mais completa inércia. E, se a inércia de Galileu é o comportamento euclidiano do ponto-partícula, a inércia de Einstein será o comportamento super-rieimanniano desse mesmo ponto. De acordo com a teoria de Einstein, para certas condições simplificadoras é, com efeito, igual supormos um sistema com certo movimento ascendente, ou supô-lo, estático, num certo campo de gravitação. O princípio da relatividade, recebendo o auxílio deste novo princípio de equivalência, viria a generalizar-se procurando, em qualquer campo de gravitação, invariantes para qualquer sistema de coordenadas, acabando com a existência de observadores privilegiados. ${ }^{(19)}$ Desde logo, comentava Leonardo Coimbra, e até como simples aplicação da

\footnotetext{
(17) COIMBRA, Leonardo - (1923). p. 166.

(18) COIMBRA, Leonardo - (1923). p. 168.

(19) COIMBRA, Leonardo - (1922). p. 97.
} 
relatividade restrita a um campo de gravitação, e por virtude do princípio de equivalência, nos é impossível definir um tempo aplicável a todo o campo e um espaço cuja métrica seja euclidiana. Mas, não havendo, na interpretação de Einstein forças atractivas, sendo os campos gravíticos devidos a simples forças de inércia, é claro que o que interessa é a geometria dos movimentos dos corpos, as suas linhas de Universo. Tratava-se, portanto, de um estudo geométrico que haveria de ser feito, para o que havia a preparação anterior dos trabalhos de Gauss, estudando a geometria de certos espaços em si, sem referência a um espaço superior envolvente nem a qualquer especial sistema de coordenadas. ${ }^{(20)}$

\section{José de Almeida Lima}

Num trabalho intitulado A Física perante as teorias de Einstein, publicado em 1921, na 3a Série - no 9 do Jornal de Sciencias Matematicas, Físicas e Naturais, da Academia das Sciencias de Lisboa (também publicado em separata) Almeida Lima afirmava que a descoberta, relativamente moderna, de muitos fenómenos físicos, e, entre eles os que se supunham ser provocados pelo movimento de corpúsculos animados de velocidades, já não muito afastadas da velocidade de propagação da luz, vieram criar novas dificuldades à concepção newtoniana, originando importantes trabalhos, do que resultaram novos símbolos, abarcando dum modo mais completo, todos os fenómenos físicos conhecidos. Com efeito, Lorentz e FitzGerald imaginaram um novo símbolo: quando um corpo se desloca, a sua dimensão, cuja direcção coincide com a do movimento, diminui. Essa diminuição é avaliada por meio dum coeficiente de contracção; e, comentava Almeida Lima, cousa perturbante, o cálculo prova que se o corpo estivesse animado duma velocidade igual à da luz, a sua dimensão na direcção do movimento anular-se-ia, e, portanto, o corpo! Sobre esta hipótese, afirmava que: ${ }^{(21)}$

Para o meu senso de homem vulgar uma tal conclusão seria considerada como um absurdo, e implicaria na exclusão do símbolo de Lorentz. Contudo esta conclusão foi aceita por Einstein, e considerada mesmo como basilar nas suas teorias.

(20) COIMBRA, Leonardo - (1922). p. 98.

(21) LIMA, J. M. de Almeida: (1921). p. 5. 
As dificuldades que envolviam a teoria de Lorentz resolveram-se admitindo que o éter não existe. Contudo, para Almeida Lima sem éter não podia existir propagação ondulatória, e, portanto, estava-se a assistir à derrocada desse magnífico edifício, que tam grandes serviços prestou à sciencia e que contém no seu activo previsões maravilhosas verificadas pela experiência, como são a refracção cónica interior e exterior, a dupla polarização circular na polarização rotatória, etc. Segundo ele, a anulação do éter implicava uma grave contradição com essas teorias. Procurava justificar-se, afirmando: ${ }^{(22)}$

Sei que nessa afirmativa muitos verão uma irreverência, quasi um sacrilégio atentando contra o ídolo que beatificamente veneram; mas eu devo dizer que, para mim na sicencia é um perigo a idolatria, e, repetindo uma frase já dita: se na sciencia existissem dogmas conviria ser herege.

Atentemos bem no caso; se não existisse éter não existiriam ondulações para a luz que nos vêm dos espaços planetários e estelares; mas, como a luz, é inegável, que nos atinge, segue-se que, rejeitada a teoria da ondulação, teríamos de voltar à rejeitada teoria do Newton que, a experiência o provou, está em contradição com um facto fundamental, e isso já é grave.

Mas se a luz é constituída por um fluxo material, e se os crepúsculos que a compõem têm a tal velocidade limite, segue-se que esses crepúsculos não podem existir; logo, se o silogismo ainda é a base do raciocínio, não vejo como possa deixar de concluir-se que, a luz não existe.

Almeida Lima fazia notar que Lorentz simbolizou a sua teoria sobre os factos físicos, por meio dum conjunto de equações referidas a um certo sistema de eixos. Imaginou depois que o sistema a que essas equações se aplicavam passava por um movimento de translação uniforme dum certo espaço para outro espaço. Naturalmente resultou, dada a diferença dos espaços, uma diferença nas equações. Mas, Lorentz observou que se em vez do tempo $t$ no novo espaço considerasse um outro tempo $t_{1}$, que se chamava tempo local, o segundo sistema de equações voltava a ser idêntico ao primeiro. Parecia tra-

(22) LIMA, J. M. de Almeida: (1921). p. 5-6. 
tar-se de um artifício, banal, em análise, mas, para Einstein ... não se trata de um artifício, mas de uma realidade.

Para Almeida Lima havia uma diferença profunda entre um facto (circunstância absoluta) e a sua percepção (circunstância relativa). Ora, sendo a circunstância da simultaneidade recebida por percepção é claro que adquiria por essa razão o carácter de relatividade ou se melhor se quiser de contingência. Pretendeu esclarecer o caso com um exemplo muito utilizado. Imaginava que em dois astros, a distâncias muito diferentes da Terra, se produziam dois fortes clarões (devidos por exemplo a explosões) absolutamente simultâneos. Para um observador colocado sobre a Terra esses acontecimentos simultâneos se lhe manifestavam, necessariamente, com um intervalo de tempo tanto maior quanto maior fosse a diferença de distância dos dois astros à Terra. É claro que, inversamente, dois factos que se manifestavam simultaneamente podiam ter sido produzidos em tempos diferentes. As circunstâncias ainda se complicavam quando o corpo que emitia luz estava em movimento, aproximando-se ou afastando-se do observador, porque, no primeiro caso, a revelação do fenómeno fazia-se em menor tempo e no segundo em maior tempo. A este facto ainda podia sobrevir uma nova complicação resultante da variabilidade do espaço, devido por exemplo, a um campo de gravitação, que desviasse a luz ou acelerasse ou retardasse o seu movimento. Segundo ele, ${ }^{(23)}$

Estamos, pois, em pleno campo da relatividade, em presença da realidade das cousas que nos é dada pela sua percepção, e fatalmente dum modo contingente.

Não há, pois dúvida, que Einstein viu bem o fundo da realidade; o tempo real é efectivamente relativo ou contingente.

\section{Armando Cyrilo Soares}

No ano de 1922 Cyrilo Soares apresentou em concurso para professor de Física da Faculdade de Ciências de Universidade de Lisboa uma dissertação intitulada $O$ conceito de matéria na evolução das teorias físicas. Neste tra- 
balho incluía a análise do conceito de matéria nas teorias modernas, dedicando particular atenção ao conceito de inércia no contexto da Teoria da Relatividade.

Cyrilo Soares considerava insustentáveis as noções de espaço e tempo absolutos da mecânica de Newton. Assim, a distância espacial ou o intervalo de tempo entre dois acontecimentos num dado sistema dependiam do estado de movimento do observador e do sistema. Segundo ele, as noções da relatividade do espaço e do tempo são as primeiras consequências lógicas dos princípios em que assenta a Teoria da Relatividade Restrita (primeira forma da teoria de Einstein) e que são: o princípio da relatividade, que estende às leis de todos os fenómenos físicos a invariância já estabelecida pela mecânica clássica para as leis mecânicas em todos os sistemas em translação uniforme, relativamente uns aos outros; e o princípio da isotropia da propagação da luz, que consiste em admitir que num sistema sem aceleração, a luz se propaga em todas as direcções com a mesma velocidade constante, independentemente do movimento da origem luminosa. Afirmava que, depois da relatividade do espaço e do tempo, se estabelece a relatividade da velocidade, da inércia e, em geral, a relatividade dos fenómenos físicos cujas leis serão as mesmas para todos os observadores que façam parte dos sistemas em que eles se passam, embora estes sistemas estejam em translação uniforme, uns em relação aos outros, mas que serão diferentes para um observador ligado a um sistema em movimento relativamente àquele em que os fenómenos se realizam. ${ }^{(24)}$

No seu estudo, Cyrilo Soares salientava que considerações de ordem teórica, o estudo experimental dos fenómenos e as experiências de Rowland faziam considerar uma inércia de origem electromagnética que para um corpo electrizado em movimento se devia adicionar à sua inércia própria. Considerava inércia como uma função da velocidade, dependendo além disso da direç̧ão que se considerava relativamente à direcção do movimento de que está animado o corpo. Distinguia dois aspectos: os coeficientes de inércia longitudinal e de inércia transversal. Organizada sobre estas ideias e assumindo certas hipóteses adequadas à dinâmica especial duma partícula electrizada em movimento, Max Abraham e Lorentz estabeleceram de modos diversos a relação de dependência entre inércia transversal $m$ e a velocidade $v$. Cyrilo Soares considerava a relação de Lorentz mais simples do que a de Abraham e mais conforme aos resultados experimentais, e podia traduzir-se

(24) SOARES, A. Cyrilo: (1922). p. 66-67. 
pela expressão:

$$
m=\frac{m_{o}}{\sqrt{1-\frac{v^{2}}{c^{2}}}}
$$

em que $m_{o}$ representa a inércia inicial, ou da partícula em repouso, e $c$ a velocidade da luz no vácuo. ${ }^{(25)}$

Daí estarmos perante uma nova mecânica, cuja confirmação era observada na sua aplicação aos electrões animados de grandes velocidades que constituem os raios catódicos e os raios $\beta$. Com efeito, referia Cyrilo Soares, determinadas experimentalmente, a velocidade, a razão e $/ m$ entre a carga eléctrica e e a inércia transversal $m$ das partículas catódicas e dos raios $\beta$, e considerando e constante para cada partícula e com o mesmo valor para todas, foi possível a Kaufmann determinar os valores da razão entre a inércia transversal $m$ correspondente à velocidade $v$ duma partícula e o valor do mesmo coeficiente $m_{o}$ para velocidades extremamente pequenas em que se pode considerar constante.

Como um dos mais notáveis resultados da Teoria da Relatividade, Cyrilo Soares apontava, ainda, a demonstração de que a energia total $\mathrm{E}$ dum corpo animado da velocidade $v$ se calculava pela expressão

$$
E=m c^{2}
$$

fazendo notar que a cada variação da inércia dum corpo correspondia uma variação da sua energia total e reciprocamente; ou por outras palavras:

- Toda a inércia $m$ representa uma energia total $m c^{2}$

- A toda a energia $E$ corresponde uma inércia $E / c^{2}$

Deste modo, concordava com a hipótese de que toda a absorção ou emissão de energia por um corpo acarreta uma variação da sua energia total e uma variação da sua inércia proporcional à primeira. Assim, para Cyrilo Soares, a mudança de temperatura, as reacções químicas, as transformações radioactivas, etc., deviam ser outras tantas causas da variação da inércia dum corpo. A inércia e a energia deviam, então, ser considerados dois aspectos da mesma coisa. Medir a matéria dum corpo pela sua inércia era, pois, medi-la como quantidade de energia.

(25) SOARES, A. Cyrilo: (1922). p. 62. 
No seu estudo, Cyrilo Soares referia-se aos estudos de Gustav Le Bon publicados com o título L'Évolution de La Matière, para quem a matéria e a energia são duas formas da mesma substância e a justificar o conceito de matéria, formulado pela Energética. Tendo também como referência o trabalho de Jean Becquerel intitulado Exposé elementaire de la Thèorie d'Einstein, considerava que no princípio da conservação da energia se fundiu o princípio da conservação da inércia ou da massa. Mas, se a inércia dum corpo corresponde, como Einstein demonstrou, à sua energia total, isto é, se toda a inércia do corpo é devida às energias que este contém, Cyrilo Soares concluía que: ou que a matéria não é dotada de inércia, ou que a matéria não é essencialmente distinta da energia e apenas representa as combinações mais ou menos complexas e mais ou menos estáveis de energias diversas que constituem os corpos. Adoptando a segunda hipótese afirmava que a massa é a quantidade de matéria e media-se pela inércia inicial. Acrescentava ainda que a quantidade de matéria dum corpo não é em rigor uma constante. Contudo, por serem em geral pequenos os acréscimos positivos que sofrem as energias componentes dos corpos, em relação ao seu valor total, se considerava praticamente invariável a sua massa. Concluía que a medida newtoniana de massa, sem atender ao estado do corpo, constituía, portanto, uma aproximação suficiente. ${ }^{(26)}$

Fazendo uma breve referência à Teoria da Relatividade Generalizada Cyrilo Soares afirmava que dando à sua teoria uma forma mais ampla (relatividade geral), de modo a aplicar-se ao caso dum sistema em movimento acelerado, Einstein mostrou a equivalência entre uma aceleração e um campo de gravitação e estabeleceu que a energia pesava proporcionalmente à sua inércia, o que concordava com os resultados das experiências de Eotovos. Em consequência, um raio de luz devia encurvar-se num campo de gravitação suficientemente forte. Calculado por Einstein, o desvio que a luz proveniente duma estrela deveria sofrer passando próxima da superfície do Sol, foi confirmado pelas observações astronómicas realizadas durante o eclipse total do Sol em Maio de 1919. ${ }^{(27)}$

(26) SOARES, A. Cyrilo: (1922). p. 76. 


\section{Melo e Simas}

Nos Dados Astronómicos para os Almanaques de 1924 para Portugal, do Observatório Astronómico de Lisboa, publicados em 1922, Melo e Simas afirmava que a Teoria da Relatividade girava, principalmente, em torno das noções de espaço, tempo e, por conseguinte, movimento e matéria. Neste contexto, por espaço devia entender-se, não o espaço absoluto, isto é, o espaço representado apenas na concepção das suas três dimensões, o espaço amorfo, inerte, cuja significação só por si nada dizia e que constituía uma simples abstracção do nosso espírito; mas sim o espaço relativo, o espaço que podia medir-se, ou com uma unidade vulgar, ou pelo tempo que um corpo animado de velocidade conhecida leva a percorrer as suas dimensões. Por tempo deveria entender-se igualmente o tempo relativo, isto é, o intervalo de tempo que pode avaliar-se, quer pelo relógio, quer pela sucessão isócrona do mesmo ou de idênticos fenómenos, e não o tempo em si, sem origem nem finalidade, o tempo em que todos falam e ninguém compreende, que antes se não conseguiu definir, e que constituía outra abstracção do nosso espírito. ${ }^{(28)}$

Tratando pois a Teoria da Relatividade, principalmente da situação e movimento de corpos no espaço e no tempo, tornava-se indispensável que esses corpos se referissem a certas origens ou pontos de vista, atendendo a que a variação de origem ou ponto de vista modifica sempre o aspecto sob o qual esses corpos se apresentam ao observador. Isto consegue-se, segundo Melo e Simas, pelo emprego das coordenadas, que não são mais do que a forma geométrica de considerar os aspectos em várias direcções. Assim, o corpo que se sabe existir sobre uma superfície fica localizado considerando-o sob dois aspectos. Se existe imóvel no espaço, são precisos trệs aspectos para a sua definição. Contudo, se se move nesse espaço, torna-se indispensável a consideração do tempo, o qual entra assim como um quarto aspecto destinado a marcar o momento a que a localização se refere. Melo e Simas fazia notar que as coordenadas do espaço poderão, conforme as circunstâncias, ser contadas quer sobre rectas perpendiculares ou não aos eixos ou planos coordenados, quer sobre curvas obedecendo a leis de continuidade arbitrárias ou determinadas; mas, em todo o caso, é sempre ao conjunto dos elementos necessários para determinar, em certo momento, a posição de um corpo que

(27) SOARES, A. Cyrilo: (1922). p. 69-70.

(28) SIMAS, M.S. de Melo e: (1922). p. 4.5. 
se move, isto é, é sempre ao sistema de coordenadas do espaço conjuntamente com o tempo contado a partir duma certa época que Simas designava sob o nome genérico de sistema. ${ }^{(29)}$

Neste contexto, para Melo e Simas, a Teoria da Relatividade é a teoria da representação das leis físicas por formas idênticas, embora essa representação se faça relativamente a sistemas diversos de referência ou tenham de substituir-se por outras equivalentes as forças hipotéticas a considerar. É a teoria pela qual se exprime que os movimentos observados são sempre relativos, isto é, que a aparência resultante do movimento de um corpo tanto pode ser explicada pelo movimento real desse corpo, como pelo deslocamento daquele ou daqueles que lhe servem de referência, como ainda pelo de certas regiões ou pontos do espaço incluindo o ocupado pelo observador; e que, se esse movimento for devido a forças actuando constantemente pode admitir-se, com certas restrições, produzido por vários modos de aplicação dessas forças, como por exemplo, o comboio em andamento e que tanto pode supor-se puxado pela máquina colocada na frente, como empurrada por ela na retaguarda. Assim, é a teoria segundo a qual só tem objectividade o que é relativo.

Experiências do fim do século XIX, que Melo e Simas considerava aliás não completamente isentas de crítica, vieram mostrar que a velocidade da luz parece ser uma constante absoluta da Natureza independente da velocidade do corpo que a recebe como é da velocidade daquele que a emite. Foi este resultado importantíssimo (que se não deve perder de vista) que orientou o espírito de Einstein para a nova teoria, aliás já intuitivamente entrevista por Lorentz sob um aspecto diferente. Melo e Simas comentava que: ${ }^{(30)}$

A razão ... porque só agora um princípio evidente manifesta resultados surpreendentes é esta: Até aqui aplicava-se ele apenas aos corpos no espaço; mas a descoberta da constância da velocidade da luz generalizou-se ao tempo, e daí surgiu uma revolução.

Um dos princípios de toda a teoria física consiste em colocar em equação o problema que essa teoria pretende resolver; isto é, consiste em dispor os princípios fundamentais por forma que eles possam ser expressos matematicamente, entregando assim o raciocínio matemático posterior e à sua

(29) SIMAS, M.S. de Melo e: (1922). p. 46.

(30) SIMAS, M.S. de Melo e: (1922). p. 47. 
lógica segura e infalível o cuidado de tirar as ilações, as quais, se a teoria é verdadeira, serão, por sua vez, confirmadas pela experiência ou pela observação. Tal era o objectivo da Teoria da Relatividade. Neste contexto, dizer, com efeito, que dois corpos apresentam movimentos relativos idênticos, quando observados de pontos de vista diferentes, traduz-se matematicamente exprimindo esses movimentos por formas idênticas relativamente a sistemas que tenham por origem aqueles pontos de vista.

Segundo Melo e Simas, o processo clássico, seguido por Einstein na sua exposição, e por todos os que depois compendiaram o assunto, foi dividir o princípio da Relatividade em dois: Um, simples - o princípio da relatividade restrita - aplicável só a corpos animados de movimento rectilíneo e uniforme; e o outro, difícil, de dedução extremamente complicada - o princípio da relatividade geral - aplicável à matéria animada de qualquer movimento. Na sua opinião, poder-se-ia, duma forma genérica, não atender à separação, visto que o primeiro princípio não é mais do que um caso particular do segundo. Como porém este último só pode deduzir-se apoiado na consideração daquele, tornou-se conveniente conservar a separação tanto sob o ponto de vista científico, como sob o ponto de vista histórico. Comentava que: ${ }^{(31)}$

Todos estes resultados (da Teoria da Relatividade), verdadeiramente extraordinários, seriam na verdade de molde a modificar toda a mecânica e mesmo a geometria correntes e suas aplicações, se as influências produzidas não fossem excessivamente pequenas e mesmo impossíveis de verificar como os instrumentos da mais alta precisão, salvo em casos especiais, como alguns que a Astronomia faculta à observação, e em que essas influências se acumulam com a sucessão dos tempos. Desta forma a geometria e a mecânica clássica continuarão a representar os fenómenos com uma aproximação suficientemente rigorosa para as aplicações da prática corrente, contribuindo a Teoria da Relatividade com mais um termo para a série de aproximações sucessivas que, pouco a pouco, conduzirão à verdade.

(31) SIMAS, M.S. de Melo e: (1922). p. 50. 


\section{Augusto Ramos da Costa}

Ramos da Costa, no seu trabalho intitulado Espaço, Matéria, Tempo ou trilogia einsteiniana, estabeleceu como objectivo da Teoria da Relatividade a procura das leis ou regras, servidas por um formalismo matemático, que se reportassem a todos os fenómenos físico naturais, referidos a sistemas de referência não dependentes do estado de movimento do observador. Einstein formulou a sua Teoria da Relatividade Restrita (1905), obtendo as leis a que podem ser submetidos os fenómenos físico naturais, para todos os sistemas, no estado de translação uniforme, depois de Michelson ter revelado o desacordo suscitado entre a sua experiência e as previsões baseadas nos conceitos antigos de espaço e tempo, desacordo que foi comprovado pelas experiências de Rayleigh e Brace (1902 e 1904) e Trouton e Noble (1903). Foi a partir da indissolubilidade da união espaço-tempo, criada por Minkowski (1908), que Einstein obteve as leis a que podem ser submetidos todos os fenómenos físico naturais, para todos os sistemas de coordenadas quadridimensionais curvilíneas. Esta formulação, conjuntamente com a inclusão do fenómeno da gravitação no campo da Relatividade, generalizando assim o princípio da Relatividade Restrita, estava na base da Teoria da Relatividade Geral. ${ }^{(32)}$

Reflectindo sobre o conceito de Espaço, Ramos da Costa afirmava ser uma concepção filosófica que, por si, nada exprime, mas que, subjectivamente, nos sugere a ideia de extensão. Neste sentido, o que importa ao físico é obter um meio de determinar os fenómenos de movimento, no espaço vazio. Por isso, para definir, no espaço, o lugar de um objecto, ou local onde se produz um fenómeno, tornava-se imprescindível recorrer ao sistema de referência. Daqui, concluía que a concepção do espaço é uma coisa essencialmente relativa, de modo que um corpo, que, para nós, está imóvel no espaço, pode deixar de estar para outros observadores. Segundo ele, a maioria das leis sobre os movimentos dos corpos mecânicos, assentava na ideia de um sistema de eixos astronómicos, designados por eixos absolutos. Contudo, no estado actual da ciência, era questionável se um tal sistema de eixos resolveria o problema em toda a sua plenitude. Com efeito, se em vez de um sistema de eixos absolutos, fosse considerado um sistema animado de rotação, em relação aos eixos absolutos, as leis da física matemática deixavam de ser

(32) COSTA, A Ramos da. (1923). p. 1. 
eficazes. Esta circunstância já tinha sido perfeitamente acentuada por Newton, o qual insistiu sempre em que: As leis da sua mecânica só são verdadeiras para os eixos absolutos e não para os eixos em rotação. Logo aí, fazia notar Ramos da Costa, havia a necessidade de se considerarem duas mecânicas: a mecânica clássica ou de Newton, verdadeira apenas para os eixos absolutos; e a mecânica relativista verdadeira para os eixos em rotação. No entanto, a experiência de Michelson provou à evidência que os eixos absolutos são inacessíveis. Foi após o insucesso das tentativas de Michelson, que Einstein estabeleceu a subsequente conclusão lógica: Na Natureza não existem eixos absolutos ou, melhor, o espaço absoluto ou o éter cósmico em quietação.

Para Ramos da Costa, a noção do espaço absoluto derivou da ideia do sólido perfeito ou, ainda, da invariância das formas geométricas. A noção da simultaneidade absoluta, era uma consequência da possibilidade de uma propagação instantânea e, deste modo, uma figura geométrica teria uma forma absoluta, independentemente do estado de movimento do sistema de referência. Enquanto, na formulação clássica a noção do espaço absoluto implicava a simultaneidade absoluta que, por sua vez, tinha subjacente o conceito da acção instantânea à distância, na Física moderna, esta ideia era completamente rejeitada. A experiência de Michelson veio corroborar a inexistência da acção instantânea à distância, pelo desacordo suscitado entre a mecânica newtoniana e as leis do electromagnetismo. ${ }^{(33)}$

O princípio de inércia, ou de Galileu, estava associado a uma noção de espaço que, segundo Ramos da Costa, era puramente teórico, porquanto difícil seria subtrair um corpo a toda a acção externa e, muito principalmente, à da gravitação, na medida em que não há região no espaço, onde ela não se faça sentir. Desta forma, a noção de espaço deveria ser reformulada. Einstein, nas medidas de comprimento, considerava duas categorias fundamentais distintas: uma, na qual o operador e o comprimento mensurável se encontram no mesmo sistema, isto é, em repouso relativo; outra, estando em sistemas diferentes, isto é, o observador movendo-se em relação ao comprimento a medir, ou reciprocamente. Enquanto a primeira era um caso geral de geometria, a segunda ultrapassava o seu domínio, pelo facto desta medida não ser independente do tempo. Ramos da Costa afirmava que: ${ }^{(34)}$

(33) COSTA, A Ramos da. (1923). p. 7-8.

(34) COSTA, A Ramos da. (1923). p. 10. 
Foi n'esta situação que Einstein, usando da liberdade que permite aos fisicos procurar uma hipothese plausível para a não concordancia dos dois generos de medição, se serviu do principio de contracção de Lorentz (1903); mas sem contudo acceitar o caracter absolutista que este imprimiu ao seu princípio, no sentido de salvaguardar as leis da mecanica classica e a noção do tempo absoluto de que esta deriva.

Deste modo, em cada observação verificam-se circunstâncias especiais, com referência ao observador e ao objecto que se visa no espaço. Assim, comentava Ramos da Costa, o que vemos, não depende só do objecto visado, mas das nossas próprias circunstâncias: posição, movimento e, sobretudo idiossincrasia pessoal. As qualidades que podem afectar o observador no exame dos objectos são: posição, movimento e grandeza. A idiossincrasia pessoal pode ser eliminada com o emprego de aparelhos científicos para medição, embora os seus resultados sejam, ainda, função da posição, movimento e grandeza dos instrumentos.

Ramos da Costa salientava o facto de que depois da Teoria da Relatividade Generalizada, as propriedades geométricas do espaço passaram a depender da distribuição da matéria, isto é, nada se podia dizer sobre a sua estrutura, sem se conhecer o estado da matéria. Isto significava que o Universo possui uma estrutura geométrica conexa da presença da matéria ou da energia electromagnética. O campo gravítico, que domina na vizinhança destes elementos, não é mais do que uma deformação do espaço-tempo. Os adeptos da escola einsteiniana evocavam a hipótese do hiperespaço, ou espaço a mais de três dimensões, sustentando a ideia de que, na teoria relativista, o espaço e o tempo estão indissoluvelmente ligados, como preconizou Minkowski, numa conferência, realizada em 1908, em Colónia. Acerca do espaço quadridimensional, Ramos da Costa comentava que: ${ }^{(35)}$

...Minkowski concebeu um mundo fisico composto d'um certo numero de fenomenos isolados, sendo cada um d'elles determinado por três coordenadas d'espaço e uma coordenada de tempo, de modo a constituir um continuum quadridimensional, visto que exis-

(35) COSTA, A Ramos da. (1923). p. 14. 
tem, para todo o fenomeno, fenomenos tão próximos, quanto se quiser, do primeiro fenomeno considerado.

Perante uma mudança tão profunda nas noções de espaço e tempo, comentava que:

É certo que não estamos habituados a encarar o mundo, como um continuum quadridimensional, por isso que o tempo na fisica, antes da theoria da Relatividade, significava uma quantidade absoluta, isto é, independente da posição e do estado de movimento do sistema de referencia; porém, ao presente, a theoria da Relatividade obriga a considerar o mundo, como um continuum quadridimensional, porque o tempo não é mais independente.

A Teoria da Relatividade conduziu à necessidade da reformulação do conceito de massa, assunto que também constituiu objecto de análise de Ramos da Costa. A definição de massa, segundo Newton, admitia a proporcionalidade entre a força que actua sobre o corpo e a aceleração que ela lhe imprime e era uma grandeza constante. Ora, esta constância, a qual, conjuntamente com o princípio da independência dos efeitos de uma força, serviu de base à mecânica newtoniana, já não podia continuar a ser aceite. Com efeito, se a força aplicada ao corpo aumentasse indefinidamente, a velocidade deveria também aumentar indefinidamente, o que é contrário à hipótese de Lorentz, que admitia que nenhuma velocidade pudesse exceder a da luz, e ao principio da isotropia, que diz que esta velocidade é finita e constante (Michelson). Ramos da Costa fazia notar que, ainda assim, esta noção de massa podia subsistir, na teoria relativista, no caso do corpo estar em repouso em relação ao observador, pois que, quando se lhe aplica uma força, a sua aceleração, no começo do movimento, é proporcional à força, sendo a relação destas duas quantidades, designada por massa em repouso ou massa inicial. Mas, uma vez o corpo em movimento, esta relação crescia com a velocidade, tendendo para infinito, à medida que a velocidade tendia para o limite superior, sendo designada por massa de inércia. ${ }^{(36)}$

Pronunciando-se, no contexto da Física moderna, sobre a hipótese de que a matéria é de origem electromagnética, Ramos da Costa partilhava da ideia de que, a par da inércia mecânica, existia também a inércia eléctrica. Neste sentido, podia imaginar-se que a matéria é constituída por corpúsculos

(36) COSTA, A Ramos da. (1923). p. 23. 
electrizados, denominados electrões, os quais, segundo Poincaré, seriam orifícios no éter, em torno dos quais este se agita. Segundo este modelo, esses orifícios seriam tanto menores quanto maior fosse a agitação do éter e, por consequência, a inércia, o que implicava que a inércia de todas as partes componentes dos átomos, isto é, de toda a matéria, fosse de origem electromagnética. Deste modo, a teoria electrónica de Lorentz consistia na inversão da relação tradicional existente entre a matéria e a electricidade, procurando explicar electricamente os fenómenos mecânicos, em vez de explicar mecanicamente os fenómenos eléctricos. Esta nova teoria vinha dar consistência à afirmação que a matéria, substrato de fenómenos mecânicos, é de origem electromagnética. Mais tarde, a desmaterialização da matéria, concebida pelos físicos ingleses, veio mostrar que a matéria se subtiliza e que a energia se materializa. Segundo esta ideia, a massa do electrão não podia ser atribuída a um suporte material que não existia, nem ao éter, cuja existência parecia apenas ser hipotética mas, era a sua própria energia a sua única realidade substancial. Ramos da Costa entendia a massa como capacidade de energia cinética, determinada pela relação entre o dobro da energia cinética e o quadrado da velocidade. Assim, considerando que a massa e a energia eram equivalentes em primeira aproximação, e por analogia com o equivalente mecânico do calor, foi criado o equivalente mecânico da massa (energética), que é a quantidade de energia contida na unidade de massa. Os trabalhos recentes de Gustav Le Bon sobre a dissociação da matéria evidenciavam que a maior quantidade de energia, que se podia extrair de um corpo, correspondia à projecção dos seus elementos no espaço, com a maior velocidade realizável. Para Le Bon, ela era igual ao semiproduto da massa pelo quadrado da velocidade limite (velocidade da luz). Ramos da Costa comentava que este valor seduz a imaginação mais potente em conceber possibilidades ilimitadas em prol da indústria humana. Deste modo, tornava-se provável que, num futuro mais ou menos próximo, o conhecimento desenvolvido na era da radioactividade pelas mãos de Bequerel e Curie, tornasse possível descobrir forças extraordinárias capazes de aniquilar as forças intra-atomicas que mantinham pela coesão, o equilíbrio dos agregados de átomos.

Deste modo, a energia total, adquirida por uma partícula de matéria, depois da Teoria da Relatividade Restrita, passaria a compor-se: da energia que encerra a matéria em repouso, que é a soma das energias cinética e potencial dos electrões que constituem; e da energia cinética devida à velocidade da partícula, em relação aos observadores considerados (energia esta que cresce 
indefinidamente à medida que essa velocidade tende para a velocidade da luz). Ramos da Costa referia que: ${ }^{(37)}$

... aquela energia é fantástica, pois que um gramma corresponde à presença d'uma energia interna egual a $9 \times 10^{20}$ ergs, provém quasi toda de nucleos atomicos, e da qual, uma pequena porção é libertada expontaneamente nas transformações radioactivas, e uma outra, bastante menor, proveniente exclusivamente dos electrons que gravitam, em torno d'esses nucleos, evola-se na radiação (calor radiante, luz, raios $X$ ) ou nas reaç̧ões químicas. À forma de energia, manifestada durante a dissociação da materia, dá-se o nome de energia intra-atomica. Esta energia, pela sua concentração, extraordinária potencia a estabilidade d'equilibrio, differe de todas as outras fórmas, conhecidas na sciencia por energias intermolecurlares.

Concluía o seu comentário afirmando que:

Devida à grandeza da energia intra-atomica, é que os fenomemos radioactivos se manifestam tão intensamente; e como na Natureza os corpos são todos, mais ou menos, radioactivos, embora muitas das suas manifestações escapem à nossa investigação, inutil será encarecer o importantissimo papel que a materia tem a desempenhar, como colossal reservatório da energia intra-atomica. A energia e a materia são, por consequencia, duas fórmas diversas da mesma coisa, em que a materia representa uma fórma relativamente estável da energia intra-atomica, e o calor, a luz, a electricidade, etc. representam fórmas mutáveis da mesma energia.

Para Ramos da Costa, o dualismo fundamental da massa e da energia terminou no momento em que a Teoria da Relatividade, conjuntamente com a teoria dos quanta de Planck, conduziu a aproximar estas duas noções, dotando-as de propriedades comuns. Deste modo, a massa deixou de ser uma quantidade constante, e o princípio da conservação da massa, formulado por Lavoisier, veio a fundir-se com o da conservação da energia. 
No mesmo trabalho, Ramos da Costa desenvolveu algumas considerações sobre a Teoria da Relatividade Geral. Segundo ele, a sua origem parecia dever ser atribuída a dois aspectos essenciais:

19) Ao facto de Einstein não aceitar que um sistema de coordenadas - sistema de referência - possa alterar a realidade e, portanto, julgar impossível que a realidade dependa do sistema que se escolhe para estudar;

$2^{\circ}$ À inclusão do fenómeno da gravitação no campo da Relatividade.

O princípio da Relatividade Restrita aplicava-se, apenas, ao sistema de coordenadas em movimento rectilíneo e uniforme, o que, na opinião de Ramos da Costa, representava uma situação de privilégio na Natureza, porquanto, o natural é o movimento ser variado. Por isso, se tornou necessário encontrar um sistema de referência que fosse possível adaptar a todo e qualquer movimento, a fim de que todas as leis fisico-naturais pudessem ser formuladas independentemente do sistema de eixos coordenados. A inclusão do fenómeno da gravitação no campo da Relatividade resultava da equivalência, deduzida por Einstein, entre um campo gravítico e um campo de força, devido a um estado de movimento acelerado. Neste contexto, Ramos da Costa punha em evidência que até a própria luz, como massa pesada que era, estava sujeita à atracção universal, o que obsta a que a sua velocidade fique constante durante todo o percurso do raio luminoso, o que é contrário ao principio basilar da isotropia da luz. A gravitação não devia, contudo, ser apreciada como uma força aplicada a um corpo. Ramos da Costa partilhava a opinião de deveria ser entendida como uma força de inércia e da mesma natureza que aquela, que se dá num sistema acelerado. ${ }^{(38)}$

Não obstante a identidade entre a massa inerte e a massa pesada ter sido registada na mecânica clássica, nunca ela foi devidamente interpretada, o que, na opinião de Ramos da Costa, só com a mecânica relativista, após o conhecimento do princípio de equivalência entre um campo gravítico e um campo de força, devido a um estado de movimento acelerado, conduzia a admitir que a força de gravitação é uma força de inércia. Segundo ele, Einstein tinha che- 
gado a esta asserção, partindo da hipótese da geometrização da Física, ou antes, da hipótese de que uma transformação conveniente de coordenadas, nas proximidades de um ponto, é equivalente a uma força gravítica. Com efeito, Einstein generalizou a Teoria da Relatividade, estabelecendo o princípio seguinte: Todos os sistemas de referência são equivalentes para formular as leis da Natureza; estas leis são covariantes, isto é, dadas num sistema de referência, elas são dadas ao mesmo tempo, em todo e qualquer outro sistema, em face da transformação de coordenadas arbitrárias. ${ }^{(39)}$ Para Ramos da Costa, esta generalização impunha-se, visto as leis científicas serem todas baseadas na constatação de coincidências no Universo ou, antes, de intersecções de linhas do Universo, absolutas e, portanto, independentes de todo o sistema de coordenadas. Além disso, segundo ele, as leis naturais devem ser expressas sob uma forma intrínseca, isto é, sob uma forma que fique a mesma, qualquer que seja o sistema de coordenadas escolhido para estudar os fenómenos.

Na opinião de Ramos da Costa a Teoria da Relatividade surgiu como uma consequência inevitável da evolução da ciência, que se articulava com a descoberta da radioactividade, em que as velocidades dos electrões e dos raios $\beta$, se aproximam da velocidade da luz, tornando necessário adequar a mecânica ao estudo desses fenómenos. ${ }^{(40)}$

\section{Gago Coutinho}

Na sua Tentativa de interpretação simples da Teoria da Relatividade restrita, publicada pela Imprensa da Universidade, no ano de 1926, Gago Coutinho deixou bem expressa a sua opinião contrária à Teoria da Relatividade de Einstein e que combateu ao longo de toda a década de trinta nos diversos artigos que publicou. Começava logo por admitir que na nossa ignorância sobre a mecânica da propagação da luz, não se podia considerar provada a constância da sua velocidade através dos móveis, ou seja a sua isotropia. Segundo ele, a luz vinda de fora da Terra - como se conclui pela aberração - parece penetrar na atmosfera como um projéctil, apresentando uma

(39) COSTA, A Ramos da; (1923). p. 52

(40) COSTA, A Ramos da; (1923). p. 61 
velocidade composta com a velocidade da Terra. Considerava que quanto à Luz produzida na Terra, as coisas se passavam como se o éter, ou o meio onde se propaga a luz, acompanhasse a Terra, e a luz fosse dotada de inércia, como um projéctil. Contudo, no problema abstracto formulado pelos relativistas, a luz obedecia ao princípio da isotropia da propagação em todas as direcções, independentemente de considerações físicas. ${ }^{(41)}$

Gago Coutinho considerava que os relativistas não podiam afirmar seguramente que a Teoria da Relatividade tinha confirmação experimental. Num texto publicado na Seara Nova, em 1930, intitulado A Relatividade: Objecções, paradoxos, cálculos aritméticos, apresentava a seguinte objecção: ${ }^{(42)}$

É corrente ler-se em escritos relativistas que a experiência confirmou brilhantemente a Teoria da Relatividade de Einstein.

Ora os factos não falam tão claro como se conta. Já vimos que a aplicação das fórmulas de Einstein, a mais de um par de sistemas, é impossível; e é este o caso da passagem da Luz ao longo de tubo de líquido móvel de Fizeau, experiência esta que provou um arrastamento parcial da luz pelo líquido em movimento. A nova fórmula da composição de velocidades permitiria explicar este arrastamento. Mas ainda mesmo que desaparecesse aquele absurdo de as velocidades compostas dependerem de relógios que, no mesmo instante, marcam duas horas diferentes, o facto é que a fórmula de composição de velocidades relativista, - isto é, sem ser por soma algébrica é comum a várias outras teorias diferentes; portanto, ainda que a propagação da Luz nos líquidos em movimento obedecesse, de facto, àquela fórmula (independentemente de o relâmpado ter sido produzido ou não no seio do líquido), ficaríamos ignorando qual daquelas numerosíssimas teorias seria confirmada.

Segundo Gago Coutinho, as fórmulas que traduzem analiticamente o problema da Relatividade Restrita podem ser deduzidas partido das hipóteses clássicas usuais, sobre distâncias rígidas e tempo absoluto, a que corresponde a noção de só ser simultâneo o que se passar à mesma hora de relógios idên-

(41) COUTINHO, Gago: (1926). p. 5.

(42) COUTINHO, Gago: (1930). p. 28 
ticos, certos uns pelos outros na ocasião do seu contacto. Faz-se assim, nas horas e simultaneidades, uma distinção entre reais, ou absolutas, e relativistas ou aparentes. Para deduzir as fórmulas da Teoria da Relatividade partia-se, como base, do artifício dos relógios ópticos, marcando no mesmo instante absoluto horas em progressão. Assim, as deformações aparentes, tanto das dimensões como dos tempos, deviam-se à falta de simultaneidade real das observações feitas pelos habitantes dos sistemas móveis, ignorantes da existência de um sistema privilegiado, onde a luz se propaga sem produzir deformações aparentes. Gago Coutinho concluía que a medição daquelas deformações permitiria calcular as características desse sistema - ou éter - assim como a hora absoluta, independentemente da propagação da luz, a qual não é instantânea. Na sua opinião, esta hora tem realidade: é a hora de um relógio local (regulado pela rotação da Terra) transmitida mecanicamente, como seria, por exemplo, pelo transporte de cronómetros, que usam os navegadores (e os relativistas nos seus sistemas, para poderem constatar as deformações de horas e distâncias). ${ }^{(43)}$ Para ele, ao contrário das insistentes afirmações relativistas, o absoluto tem existência real. Na verdade, este começou por ser aceite na dedução das fórmulas da Teoria da Relatividade, dedução que partiu de uma posição instantânea dos sistemas, ou seja do instante absoluto, para prever o instante e aspecto óptico. ${ }^{(44)}$

Procurando colocar em evidência alguns absurdos da Teoria da Relatividade, Gago Coutinho argumentava que a regulação especial dos relógios, sua origem fundamental, varia com a rapidez de propagação do acontecimento a que pretendemos atribuir isotropia, seja som, projéctil, luz na água, luz no vácuo, gravitação, etc. Tal regulação seria pois impraticável quando se pretendesse que ela, para o mesmo móvel, se adaptasse simultaneamente a vários fenómenos concorrentes da Natureza. Donde, segundo Gago Coutinho, resultava o absurdo da Relatividade. Enfim, a Relatividade, sendo na essência o resultado da convenção fundamental proposta por Einstein aceitarmos que a luz leva sempre o mesmo tempo a percorrer distâncias iguais em qualquer sentido - forçou a atribuir aos relógios uma regulação especial, da qual terá resultado o confundirmos a aparência com a realidade, fazendonos julgar os fenómenos pelas velocidades, massas e volumes aparentes, que

(43) COUTINHO, Gago: (1926). p. 79-80

(44) COUTINHO, Gago: (1930). p. 30 
não correspondiam às noções gerais, que até então sempre tinham sido consideradas absolutas.

A própria isotropia relativista da luz, obtida por meio dos relógios ópticos, era, segundo Gago Coutinho, apenas uma ilusão de óptica. Argumentava que insistindo-se em conservar aos relógios dos sistemas móveis uma regulação absoluta, ou independente da propagação da luz ou de qualquer outro fenómeno físico, isto é, fazendo-a corresponder só à rotação da Terra - como a atribuída aos relógios comuns - pretendendo que eles, móveis ou em repouso, marcassem todos no mesmo momento a mesma hora; em uma palavra, renunciando-se a regulá-los pelo processo dos relâmpagos equidistantes, que na sua opinião resultou vicioso, ter-se-ia privado a isotropia da Luz da sua explicação relativista. ${ }^{(4.5)}$

Para Gago Coutinho, a impossibilidade de atingir uma velocidade relativista superior à da Luz era só algébrica, e resultava da maneira como os relativistas calculavam a velocidade. No seu ponto de vista, pretendeu-se contudo fugir a essa comprometedora contingência de o móvel atingir um ponto além do qual a sua velocidade passava a diminuir; e inventaram uma nova hipótese física, que na sua opinião as experiências conhecidas não justificavam: $A$ massa passaria, portanto, a ser múltipla em cada ponto material, segundo as múltiplas velocidades relativas que Ihe podemos atribuir. Colocava em evidência que foi fácil criar um coeficiente tal que, para o corpo atingir uma velocidade relativista de $300000 \mathrm{~km} / \mathrm{s}$, se tornasse necessário acumular naquele objecto uma energia infinita. Tornava-se assim impossível exceder a velocidade da Luz, além da qual se revelavam, flagrantes, os paradoxos da Relatividade. ${ }^{(46)}$ Deste modo, para Gago Coutinho, a deformação relativista imposta à massa não era física, mas apenas aparente, e derivada analiticamente do mesmo princípio da simultaneidade óptica dos relativistas, sendo análoga portanto à deformação aparente das outras grandezas aceites como rígidas. Argumentava que a salvação do princípio relativista não impunha o recurso a uma nova convenção sobre alteração física dos corpos em movimento; ainda neste ponto se podia continuar a discutir o movimento, segundo os princípios da Mecânica Clássica e respeitando a imutabilidade material da massa.

Pronunciando-se sobre as conferências feitas por Langevin em Lisboa, Porto e Coimbra no seu trabalho intitulado A Relatividade: Objecções, para-

(45) COUTINHO, Gago: (1926). p. 83-84

(46) COUTINHO, Gago: (1930). p. 23-24 
doxos, cálculos aritméticos, publicado em 1930, Gago Coutinho comentou que as recentes conferências, em Lisboa, de Paul Langevin, vieram de novo focar a Theoria da Relatividade, que uns consideravam como um raffinement da Sciência, ao passo que outros a taxavam de alucinação futurista, que pretendia amesquinhar a Mecânica. Nos seus comentários ironizava afirmando que para os relativistas, sem luz não haveria movimento, nem máquinas, nem velocidade. Gago Coutinho comentava que estes, para justificar a necessidade da aplicação das suas fórmulas, começaram por aceitar que o único meio lógico de que dispomos para sincronizar os relógios afastados - dos quais dependia a velocidade - era fornecido pelos sinais luminosos, ou electromagnéticos. Considerava que as fórmulas que traduzem analiticamente o problema da Relatividade Restrita, podiam ser deduzidas partindo das hipóteses clássicas usuais, sobre distâncias rígidas e tempo absoluto, a que corresponderia a noção de só ser simultâneo o que se passar à mesma hora de relógios idênticos, certos uns pelos outros na ocasião do seu contacto. Fazia-se assim, nas horas e simultaneidades, uma distinção entre reais, ou absolutas, e relativistas ou aparentes. ${ }^{(47)}$

Gago Coutinho colocava várias objecções à argumentação relativista. Fundamentava o seu ponto de vista fazendo notar que para que as circunstâncias fossem absolutamente idênticas em todos os sistemas móveis, e para que os seus habitantes pudessem todos verificar a isotropia da Luz, por exemplo, seria necessário aceitar que os relâmpagos luminosos, partidos do mesmo foco original, caminhassem independentes nos vários sistemas. Assim, num ponto comum de contacto veríamos passar, em instantes diferentes, relâmpagos partidos no mesmo instante do foco, o que afirmava ser um absurdo. A Relatividade procurava resolver esta dificuldade garantindo a isotropia sem que o mesmo relâmpago se dividisse. Para isso assentou em que os habitantes dos sistemas móveis, fiados na aparência dos fenómenos, poderiam ignorar as noções absolutas. As deformações aparentes, tanto das dimensões como dos tempos, eram devidas à falta de simultaneidade real das observações feitas pelos habitantes dos sistemas móveis, ignorantes da existência de um sistema privilegiado, onde a Luz se propaga sem produzir deformações aparentes.

$\mathrm{Na}$ fundamentação das suas críticas à Teoria da Relatividade, Gago Coutinho considerava que, apesar dos seus artifícios engenhosos, os relativis-

(47) COUTINHO, Gago: (1926). p. 79 
tas não conseguiram libertar-se do tempo absoluto. Afirmava que entre os múltiplos sistemas rectilíneos, dotados de movimentos uniformes, que se podiam considerar justapostos em coincidência constante, aos quais aplicava a hipótese da isotropia relativista, havia sempre um, cujos relógios estavam regulados pelos próprios relativistas exactamente como se a Luz nele se propagasse instantaneamente. Este sistema privilegiado teria relógios de marcha mais rápida do que todos os outros, e como tais relógios eram independentes da velocidade de propagação de propagação da Luz, eles eram os únicos idênticos aos relógios comuns. As velocidades determinadas por meio desses relógios do sistema privilegiado, com distâncias não deformadas, eram pois as velocidades comuns, as quais se compunham por soma. ${ }^{(48)}$ Para Gago Coutinho, Einstein foi mais restrito na sua resolução deste problema fundamental, e considerou, não o caso geral de um número de sistemas indefinido, com os seus relógios regulados todos pelo mesmo relâmpago luminoso, produzido em um ponto de contacto comum, mas agrupou os sistemas aos pares independentes. Admitiu assim mais uma hipótese que, segundo ele, não tinha experiência a confirmar: em cada par de sistemas rectilíneos a propagação da Luz é simétrica nos dois sentidos opostos; portanto, as deformações ópticas dos tempos e distâncias são idênticas, ou recíprocas.

A confirmação da Teoria da Relatividade estava, segundo Gago Coutinho, condicionada por questões práticas. Considerava impraticável comparar ou fotografar os objectos animados de velocidades de muitos milhões de metros por segundo, para lhe constatar as deformações. Assim, segundo ele, os fenómenos previstos só se discutiam em teoria; e, por outro lado, todas as deformações, tanto de extensão como de tempo, que os relativistas previam, só podiam derivar da existência teórica de relógios cuja marcha fosse absolutamente constante, apesar do seu estado de movimento. Considerava que os relativistas estavam em contradição porque, afinal, recorriam ao mesmo transporte mecânico do tempo por meio de cronómetros, o qual servia de base - para eles inaceitável - da Mecânica Clássica. Ora este recurso em teoria, para Gago Coutinho, era tão eficaz como os relâmpagos luminosos, seja para definir a mesma hora no mesmo instante, em vários pontos afastados de um sistema móvel, seja para dar aos seus relógios a décalage - ou regulação de horas em progressão aritmética - que a Relatividade impunha, para tornar geral a todos os sistemas a isotropia, ou constância da velocidade

(48) COUTINHO, Gago: (1930). p. 17 
de propagação da Luz. ${ }^{(49)}$ Esta isotropia servia de agente para regulação dos relógios afastados. O conceito de simultaneidade relativista podia ser apresentado com o seguinte exemplo: se nos colocarmos a meio da linha recta que os une, e virmos chegar simultaneamente dois relâmpagos lá produzidos, tais relâmpagos terão partido de lá, daqueles relógios equidistantes, à sua mesma hora. ${ }^{(50)}$

Gago Coutinho considerava que tal hipótese, aparentemente tão inocente como um axioma, trazia algumas consequências imprevistas. Fazia notar que embora todos tenhamos uma concepção comum, racional e perfeita do mesmo instante absoluto, o qual se refere a factos passados em pontos diferentes, ao mesmo tempo (o que verificaríamos se entre eles nos transportássemos instantaneamente, em teoria ou em pensamento), considerando assim simultâneo o que se passa à mesma hora de relógios idênticos (regulados previamente em contacto), para os relativistas só é simultâneo o que se passar à mesma hora dos relógios locais, regulados pelo processo dos relâmpagos equidistantes. O cálculo mostrava que esta simultaneidade era diferente da absoluta; mas ambas as simultaneidades, tanto a relativista como a absoluta, se prestavam a, teoricamente, lhe prevermos as consequências. ${ }^{(51)}$ Para justificar a necessidade da aplicação das suas fórmulas novas a este caso, os relativistas começavam por aceitar que o único meio lógico de que se dispunha para sincronizar os relógios afastados - dos quais dependia a velocidade - era fornecido pelos sinais luminosos, ou electromagnéticos.

Contrariando as afirmações dos relativistas, Gago Coutinho afirmava que o absoluto tem existência real. Referia mesmo que ele começou por ser aceite pelos relativistas na dedução das suas fórmulas, dedução que partiu de uma posição instantânea dos sistemas, ou seja do instante absoluto, para prever o instante e aspecto óptico. Na sua opinião, a existência desse instante absoluto e tão real, que resultava de fórmulas elementares e indiscutíveis, as quais, partindo de dados de observação directa - como seriam as coordenadas, ou horas locais dos pontos de contacto de vários sistemas, iluminados pela passagem do relâmpago sincronizante - permitiam calcular tanto a hora óptica como a absoluta, correspondente a essa posição dos sistemas, ou seja a esse instante. $\mathrm{Na}$ sua análise concluía que não foi a nossa impotência para atingir pratica-

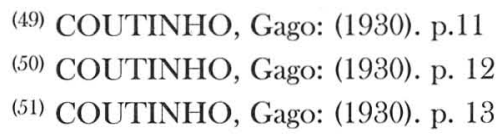


mente o absoluto, que impôs a Relatividade. Na verdade, ao lado desta Mecânica Óptica, fundada numa maravilhosa propagação da luz, continuava existindo a Mecânica Clássica, que permitiu deduzir as fórmulas da Relatividade, como permitiria deduzir outras, sónicas, hidráulicas ou gravimétricas, fundadas na isotropia do som, da luz na água, ou da gravitação. A multiplicidade destas isotropias tornava-as incompatíveis e arrastaria consequências absurdas. Na sua opinião, deveriam, portanto, ser postas todas de parte. ${ }^{(52)}$

Os artigos publicados por Gago Coutinho mereceram uma forte reacção, entre as quais se conta um artigo publicado no mesmo ano por Manuel do Reis, na Seara Nova.

\section{Manuel dos Reis}

Pouco tempo após a publicação do artigo de Gago Coutinho, no qual formulava a interrogação - Será a Relatividade em princípio absurda? - a argumentação anti relativista do almirante foi vivamente refutada noutro artigo da autoria de Manuel dos Reis, também publicado na Seara Nova (no 207 - 1930), com o título A Teoria da Relatividade e o absurdo duma crítica. Neste artigo, começou por apresentar algumas considerações sobre a Teoria da Relatividade, passando depois à contestação do controverso artigo de Gago Coutinho. ${ }^{(53)}$

Para Manuel dos Reis era incontestável que a célebre experiência efectuada por Michelson em 1881, e depois repetida com precaução crescente, confirmou a isotropia da propagação da luz. Baseado nesta experiência, Lorentz tentou salvar a hipótese do éter, explicando este resultado por uma contracção longitudinal absoluta dos corpos em movimento. Contudo, surgiram outras experiências, ópticas e eléctricas, concordantes com a de Michelson e inexplicáveis pela simples hipótese da contracção: a de Trouton e Noble e a de Rayleigh e Brace. Estas experiências convenceram Lorentz de que a electrodinâmica tinha errado gravemente negando o princípio da relatividade. Porém, ao reparar o erro, o célebre físico persistiu na sua intenção de salvar a hipótese do éter. Manuel dos Reis considerava que o resultado foi chegar a

(52) COUTINHO, Gago: (1930). p. 31

(53) REIS, Manuel dos: (1930). p. 227 - 233, $264-271$ 
uma teoria que, se não fora o embaraço cronológico, justamente poderia denominar-se uma caricatura da parte cinemática e electrodinâmica da teoria de Einstein. Lorentz começou por considerar que não havia relatividade electrodinâmica real. Contudo, a aparência parecia mostrar o contrário, e a razão fundamental disto é que o observador animado de translação uniforme, quando crê utilizar medidas exactas de espaço e de tempo, utiliza medidas incorrectas. $\mathrm{O}$ resultado das experiências conduziam à ideia de que o movimento através do éter contraía as réguas métricas, destruía o sincronismo e retardava a marcha dos relógios, sem que o observador pudesse adquirir consciência de tais alterações. As fórmulas de transformação das coordenadas absolutas de espaço e tempo obtidas por Lorentz são idênticas às que Einstein devia reencontrar um ano depois na sua memória fundamental sobre a relatividade (1905). ${ }^{(54)}$

Perante os recentes resultados experimentais, a cinemática clássica tornou-se insustentável. Com efeito, as equações fundamentais da electrodinâmica não deviam mudar de forma pela passagem dum a outro sistema de inércia. Contudo a transformação de Galileu alterava a forma daquelas equações. Manuel dos Reis salientava o facto de que esta transformação conservava a forma das equações da mecânica newtoniana, mas a experiência que verifica estas equações limitava-se apenas a velocidades muito pequenas em relação à maior velocidade conhecida, a da luz no vácuo, enquanto as equações da electrodinâmica eram verificadas por uma experiência riquíssima e de alta precisão. Assim, a cinemática clássica só tinha validade para as pequenas velocidades, dado que só nestas condições a transformação de Galileu deixava invariante a forma das equações da mecânica newtoniana. Mas parecia haver outra dificuldade. O carácter absoluto do tempo e da métrica de espaço, conforme à concepção ordinária destas duas formas expressamente formuladas por Newton como base da Física clássica, constituíam argumentos muito fortes para salvar a cinemática galileana, pelo que aparentemente parecia inatacável, considerando-se intangível.

Manuel dos Reis reforçava a ideia de que as medidas de espaço e de tempo pressupõem teoricamente que em todos os sistemas de referência estão distribuídos localmente réguas rígidas e relógios, umas e outros da mesma construção. Neste contexto o tempo absoluto teria realidade se existissem

(54) REIS, Manuel dos: (1930). p. 228 
sinais instantâneos a distância e se o movimento não influísse na marcha dum relógio. A emissão de sinais desse género permitiria estabelecer o sincronismo de todos os relógios ou verificá-lo num instante qualquer. Analogamente, a métrica de cada espaço de referência seria absoluta se o movimento não influísse no comprimento da régua. Mas, recordava Manuel dos Reis, não há sinais instantâneos à distância, nem certeza de que o movimento é indiferente ao comprimento duma régua ou a marcha dum relógio. Deste modo, as noções de tempo absoluto e métrica absoluta deveriam ser revistas. A validade das equações da electrodinâmica em todos os sistemas de inércia tinha como consequência imediata que a velocidade da Luz (no vácuo) devia ser uma constante universal. Assumindo-se esta proposição (confirmada directamente pela experiência de Michelson) como um segundo princípio, que se devia juntar ao princípio da relatividade, tinha-se como consequência um tempo próprio em cada sistema de inércia e era por meio de sinais luminosos que se verificava a perfeição e se realizava o sincronismo dos relógios do sistema.

As equações fundamentais da cinemática de Einstein, que relacionam as coordenadas de espaço e tempo dum acontecimento em dois sistemas de inércia quaisquer (transformação de Lorentz) eram uma consequência destes dois princípios. Manuel dos Reis concluía que destas equações:

- O tempo não é absoluto

- Para cada sistema, os relógios do outro sistema marcham mais lentamente que os seus e não são todos síncronos entre si

- A métrica espacial não é absoluta

- Para cada sistema, as réguas unitárias não transversais do outro sistema são mais curtas que as suas.

Estes efeitos são praticamente nulos para as velocidades ordinárias da natureza, mas se tornam enormes para velocidades pouco inferiores à da luz. A velocidade da luz não pode ser atingida pelos corpos nem ultrapassada por nenhuma outra propagação. Espaço e tempo são formas relativas, mas fundem-se numa forma de quatro dimensões (universo, Welt de Minkowski) e esta é absoluta. Manuel dos Reis partilhava a ideia de que o universo só é acessível ao entendimento. Por natureza, a percepção decompõe-o em espaço e tempo, diferente segundo o sistema rígido a que está ligado o observador. ${ }^{(55)}$

(55) REIS, Manuel dos: (1930). p. 229 
Manuel dos Reis destacava o facto de que a Teoria da Relatividade conduzia a uma mecânica diversa da newtoniana. O próprio conceito de massa deveria ser reformulado. Também ela passava a assumir um carácter relativo. Com efeito, a massa aumenta com a velocidade tendendo a tornar-se infinita se a velocidade se aproxima indefinidamente da velocidade da luz. Manuel dos Reis salientava que o produto deste aumento de massa pelo quadrado de velocidade da luz era justamente igual à energia cinética. Considerava que se estava perante um caso particular da lei da inércia da energia, segundo a qual toda a energia possui massa e reciprocamente. Para Manuel dos Reis, energia e massa não são essências distintas mas sim aspectos diferentes duma essência única.

Os artigos de Gago Coutinho e de Manuel dos Reis constituíram o ponto de partida de um largo debate público que se estendeu por toda a década de trinta, tanto através de opúsculos como em publicações na imprensa periódica. Neste debate assumiram particular destaque nomes como Rui Luís Gomes e Abel Salazar.

\section{Bibliografia}

BASTO, Egas Ferreira Pinto - Theoria dos Electrões. (1ª parte). Coimbra : Imprensa da Universidade. 1908

BASTO, Egas Ferreira Pinto - Theoria dos Electrões. (2 $2^{\underline{a}}$ parte). Coimbra : Imprensa da Universidade, 1908

BASTO, Álvaro José da Silva - Os raios cathódicos e os raios X de Röntgen. Coimbra : Imprensa da Universidade, 1897

BASTOS, Henrique Teixeira - Raios X de Rontgen. O Instituto. Vol. XLIII, p 38 41, $275-279$.

BASTOS, Henrique Teixeira - Theoria Electromagnetica da Luz. Coimbra : Imprensa da Universidade, 1885.

Carvalho, J. A. Simões de - Memória Histórica da Faculdade de Philosofia. Coimbra : Imprensa da Universidade, 1872.

COIMBRA, Leonardo - $O$ criacionismo : esboço de um sistema filosófico. Porto : Biblioteca da Renascença Portuguesa, 1912

COIMBRA, Leonardo - As doutrinas de Einstein, seu valor scientífico e filosófico. Águia. № 3, (Set. 1922), p. 96-109 
COIMBRA, Leonardo - Obras de Leonardo Coimbra. Porto : Lello \& Irmão, 1983

COIMBRA, Leonardo - O princípio da Relatividade Restrita. A Águia. Vol. X (XXX) 3롤. Série. (Abr./Jun. 1922), p. 73-81

COIMBRA, Leonardo - A razão experimental : lógica e metafísica. Porto : Renascença Portuguesa; Rio de Janeiro : Annuario do Brasil, 1923

COSTA, Augusto Ramos da - Espaço, matéria, tempo ou triologia einsteiniana. Lisboa : Imp. Lucas, 1923

COUTINHO, Gago - Tentativa de interpretação simples da "Teoria da relatividade restrita”. Coimbra : Imp. da Universidade, 1926. Sep. de “O Instituto”, 73 (3)

COUTINHO, Gago - A Relatividade : Objecções, paradoxos, cálculos aritméticos. Tip. «Seara Nova». 1930. p. 23-24.

COUTINHO, Gago - Será a relatividade em princípio absurda? : a relatividade ao alcance de todos. Seara Nova. № 200, 203, 210. 1930. p. 115-123, 163-168, 284-285

FITAS, Augusto J. Santos - A Teoria da Relatividade em Portugal no Período entre guerras. Gazeta de Física (27), Fasc. II. 2004. p. 4-10

FREIRE, Francisco de Castro - Memória Histórica da Faculdade de Mathematica. Coimbra : Imprensa da Universidade, 1872

GIRÃO, António Luiz Ferreira - A Theoria dos Atomos e os Limites da Sciencia. Porto : Livraria e editor João E. da Cruz Coutinho, 1879

LIMA, J. M. de Almeida - A Física perante as teorias de Einstein. Lisboa : Imprensa Nacional. 1921

LOBO, Costa - Explicação Física da Atraç̧ão Universal. O Instituto (61) 1917; p. 611-613.

MAGALHÃES, João de - O Rádio e a Radioactividade. Coimbra : Imprensa da Universidade, 1906

MAGALHÃES, João de - O Rádio e a Radioactividade. Coimbra. O Instituto. 1906 - 1907. (53) p. 309- 314; 357-365; 433-440; 485-493; 551-561; 614-622; 684-694; 726-737; (54) p.37-46; 98-111; 154-155.

MARTINS, Décio Ruivo - As ciências Físico-matemáticas em Portugal e a Reforma Pombalina. In O Marquês de Pombal e a Universidade. Coord. Ana Cristina Araújo. Coimbra : Imprensa da Universidade. 2000. p. 193-262.

MARTINS, Décio Ruivo - A ciência em Coimbra no século XIX. Actas do $1^{\circ}$ Congresso Luso-Brasileiro de História da Ciência e da Técnica. Ed. Comissão Organizadora do Congresso - Centro de Estudos de História e Filosofia da Ciência da Universidade de Évora. Setembro de 2001. p. 333-345. 
NAZARETH, Francisco Martins de Souza - Ionisação dos gases em vaso fechado. Coimbra : Imprensa da Universidade, 1915

REIS, Manuel dos - O problema da gravitação universal. Coimbra : Imprensa da Universidade, 1933

REIS, Manuel dos - A Teoria da Relatividade e o absurdo duma crítica. Seara Nova. 1930, nº 207. 1929-1930. p. 227- 233, 264- 271

SIMAS, M.S. de Melo e - A teoria da relatividade. Dados Astronómicos para os Almanaques de 1924 para Portugal. Lisboa : Imprensa Nacional, 1922

SOARES, Armando Cyrilo - O conceito de matéria na evolução das teorias físicas : dissertação. Lisboa : Of. Gráfica da Biblioteca Nacional, 1922 


\section{Série}

\section{Documentos}

Imprensa da Universidade de Coimbra

Coimbra University Press

2005

- U

C - 